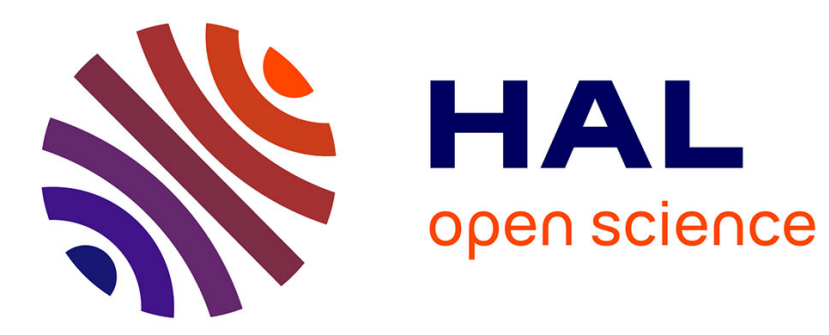

\title{
Psychiatric disorders and symptom severity in referred versus non-referred overweight children and adolescents
}

\author{
Leen Vlierberghe, Caroline Braet, Lien Goossens, Saskia Mels
}

\section{To cite this version:}

Leen Vlierberghe, Caroline Braet, Lien Goossens, Saskia Mels. Psychiatric disorders and symptom severity in referred versus non-referred overweight children and adolescents. European Child and Adolescent Psychiatry, 2008, 18 (3), pp.164-173. 10.1007/s00787-008-0717-5 . hal-00478072

\section{HAL Id: hal-00478072 \\ https://hal.science/hal-00478072}

Submitted on 30 Apr 2010

HAL is a multi-disciplinary open access archive for the deposit and dissemination of scientific research documents, whether they are published or not. The documents may come from teaching and research institutions in France or abroad, or from public or private research centers.
L'archive ouverte pluridisciplinaire HAL, est destinée au dépôt et à la diffusion de documents scientifiques de niveau recherche, publiés ou non, émanant des établissements d'enseignement et de recherche français ou étrangers, des laboratoires publics ou privés. 
Leen Van Vlierberghe

Caroline Braet

Lien Goossens

Saskia Mels

Accepted: 8 July 2008

Published online: 20 September 2008

\section{Psychiatric disorders and symptom severity in referred versus non-referred overweight children and adolescents}

L. Van Vlierberghe $(\varangle) \cdot$ C. Braet

L. Goossens · S. Mels

Dept. of Developmental, Personality

and Social Psychology

Ghent University

Henri Dunantlaan 2

9000 Ghent, Belgium

Tel.: +32-9/264-6422

Fax: $+32-9 / 264-6499$

E-Mail: leen.vanvlierberghe@ugent.be
Abstract Background This study aimed firstly to investigate whether youngsters referred for overweight treatment differ from non-referred overweight youngsters on the prevalence of psychiatric disorders and psychological symptoms. Secondly, the potentially moderating role of age, gender, socio-economic status and degree of overweight in the association of referral status and mental disorder in overweight youth was explored. Methods Participants were 155 overweight youngsters enrolled in an obesity treatment programme (mean age $=13.76$; mean BMI = 33.99) and 73 nonreferred overweight youngsters (mean age $=13.74$; mean BMI = 27.35). The Structured Clinical Interview for DSM-IV-Childhood version and the Child version of the Eating Disorder Examination were administered and participants filled out the Children's Depression Inventory, the Spence Children's Anxiety Scale and the Youth Self Report. Parents were asked to complete the Child Behavior Checklist. Results In the referred group $37.50 \%$ and in the nonreferred group $23.29 \%$ of the participants met criteria for at least one mental disorder. In both groups, anxiety disorders were most prominent. Overall, a higher prev- alence of mental disorders was found in the referred group. Referred youth displayed significantly more 'full blown' eating disorders and binge eating than non-referred youngsters and exhibited a significantly greater severity of self- and parent-reported internalizing symptoms. Referral was also associated with a significantly higher degree of overweight and significantly lower SES. After controlling for these pre-existing differences in degree of overweight and SES, only the greater severity of parentreported internalizing symptoms in referred youth remained significant. Older age was generally predictive for the presence of mental disorders and in the non-referred group SES was positively associated with psychiatric disorder. Conclusions A substantial proportion of overweight youngsters suffer from mental disorders. Referral status and age are associated with the presence of psychopathology. However, differences between referred and non-referred youngsters are not as pronounced as expected on the basis of earlier research in the field.

Key words referral status overweight - psychopathology youth 


\section{Introduction}

Although overweight is mostly referred to as a medical condition, its psychosocial comorbidity has been studied extensively [19]. However, in research on overweight in youth, structured clinical interviews, currently seen as the 'gold standard' for the assessment of psychiatric disorders [9], are rarely included. With the M-CIDI, Britz and colleagues [7] obtained lifetime psychiatric diagnoses in 33 out of 47 obese adolescents (15-21 years) referred for overweight treatment. Vila et al. [46] interviewed 155 referred obese youngsters (5-17 years) using the K-SADS-R and demonstrated current mental disorders in $56.77 \%$ of the sample. On the other hand, Lamertz and colleagues [27] found considerably lower prevalence rates. From a large-scale community survey on mental disorders in youth, the authors picked out all participants (14-17 years) with a BMI above 95th percentile $(n=86)$ and demonstrated life-time psychiatric disorders to be equal in overweight and normal weight youth $(38.80 \%$ versus $39.65 \%)$. The latter findings corroborate the results from a longitudinal study by Mustillo et al. [31], in which the percentage of overweight youngsters (BMI >95th percentile; $n=270$ ) who had suffered from a current disorder at any of the annual assessments was low (e.g. 3.00\% for mood and $2.17 \%$ for anxiety disorders). Moreover, when compared with youngsters who had never been obese during the 7-year study period, only those youngsters who were obese from childhood onwards exhibited higher levels of oppositional defiant disorder and (only for boys) depression. No other differences emerged. According to Friedman and Brownell [19], such inconsistent findings typically characterize the field and reflect methodological differences between studies on the one hand and heterogeneity within the obese population on the other hand. Therefore, these authors urge to conduct methodologically sound studies examining risk factors associated with psychopathology within groups of obese individuals.

Referral status might be one such aspect of heterogeneity. Parents of overweight youngsters referred to an obesity clinic report more symptoms of internalizing and externalizing problems in their children as compared to parents of non-referred overweight youngsters [5, 14]. In the Britz et al. study [7] a gender-matched sample of non-referred obese youngsters was composed by selecting the 47 heaviest adolescents from a large population-based control group. Referred obese youngsters displayed significantly more diagnoses of mood $(42.55 \%$ vs. $17.02 \%)$, anxiety ( $40.43 \%$ vs. $21.28 \%)$ and somatoform $(14.89 \%$ vs. $0.00 \%)$ disorders. Unfortunately, the Vila et al. study [46] did not include a non-referred sample.
More studies with state-of-the-art assessment of psychiatric disorder are needed to replicate initial findings on help-seeking as a potential source of variance within the population of overweight youngsters.

Strikingly, in the Braet et al. [5], as well as in the Erermis et al. [14] and the Britz et al [7] study, referred overweight youngsters displayed a higher degree of overweight than the non-referred group. Erermis et al. [14] entered degree of overweight as a covariate in the analyses, which clearly reduced the number of between group differences in psychological symptoms. It is unclear to what extent confounding effects of degree of overweight might have accounted for the results of the other two studies.

In adults, Herpertz and colleagues [21] demonstrated that referred obese women suffered significantly more often from at least one mental disorder than non-referred obese women, whereas for men this difference could not be established. The latter findings point at the role of gender as a moderator in the relation of referral status and psychopathology in overweight individuals. Research on psychopathology in obesity would greatly benefit from studies on the importance of degree of overweight and demographic factors $[17,19]$. To the best of our knowledge, in overweight children or adolescents, the moderating role of demographic variables and degree of overweight in the association of referral status and psychopathology has not been investigated yet.

In overweight youth, it seems especially relevant to include the assessment of eating disorders. Research suggests that childhood obesity is a risk factor for the development of eating disorders in adulthood [16]. However, the prevalence of 'full blown' eating disorder diagnoses in overweight youth is rather low. In the study by Britz and colleagues [7] three referred obese adolescents $(6.38 \%)$ obtained a diagnosis of Bulimia Nervosa (BN), another three of Binge Eating Disorder (BED) and 51.06\% reported binge eating episodes. Unfortunately, in the study by Vila et al. [46] eating disorders were not included. Lamertz et al. [27] diagnosed eating disorders in $3.85 \%$ of the overweight youngsters (BMI >90th percentile; $n=312$ ). Finally, in the study by Mustillo et al. [31] $\mathrm{BN}$ was present on at least one of the assessments in $0.63 \%$ of those youngsters who had been obese on at least one of the assessments.

The clinical interview most widely used in the literature on eating disorders is the Eating Disorder Examination [EDE: 15]. Using a modified version for children and adolescents [ChEDE: 8], Decaluwé and Braet [11] obtained current diagnoses of BED in 2 and subclinical binge eating in 18 out of 196 referred obese children and adolescents (10-16 years). Nobody received a diagnosis of $\mathrm{BN}$. Glasofer and colleagues [20] detected BED in $6.25 \%$ of the referred 
overweight youngsters in their sample ( $n=160$; age 11-18), subclinical binge eating was reported by $23.75 \%$. Finally, a study by Tanofsky-Kraff and colleagues [40] in a non-referred sample of 82 overweight 6-13 year olds revealed neither $\mathrm{BN}$ nor $\mathrm{BED}$ diagnoses. As far as we know, the ChEDE has never been used to compare prevalence rates of eating disorders in referred and non-referred overweight children and adolescents.

Youngsters presenting for treatment of overweight are those that suffer, be it merely from their overweight, from comorbid psychopathology or from both. To enhance quality of life in these children and families, their concerns should be addressed adequately and effective care presupposes an overall picture of needs. Moreover, it remains to be tested to what extent this adequate care can be attained by current limited assessment procedures and highly standardised treatment programmes. Furthermore, clinicians are faced with dropout and relapse. It could be hypothesized that treatment might be especially complicated in overweight children and adolescents with associated psychological problems. Finally, unravelling how demographic variables and degree of overweight are related to psychopathology in overweight youth enables practitioners to identify vulnerable subgroups of youngsters presenting for treatment.

To conclude, the present study aimed to (a) investigate whether referred overweight youngsters differ from non-referred overweight youth concerning the prevalence of current psychiatric disorders, (b) explore possible confounding effects of degree of overweight or demographic factors and (c) predict the presence of mental disorders by examining possible moderating effects of age, gender, socio-economic status (SES) and degree of overweight in the association of referral status and mental disorders. The use of clinical interviews, yielding only categorical outcomes, is sometimes criticised as youngsters can be undiagnosed but still impaired. Self-report questionnaires generate dimensional data, representing psychopathology on a continuum which probably does more justice to the concept. Hence, a 'multimethod approach', including both a categorical taxonomy and dimensional assessment of symptom severity seems the most comprehensive way to study psychopathology in youth. Therefore, (d) differences between referred and non-referred overweight youngsters on anxiety, depression, internalizing and externalizing symptoms were also investigated with well-validated self-report questionnaire, while taking into account possible confounding effects of degree of overweight or demographic factors. As in this respect a multi-informant approach is considered most appropriate [3], parental report was also obtained.

\section{Method}

\section{Participants}

The referred sample consisted of 115 overweight youngsters ( 69 girls; 46 boys) admitted for treatment of their overweight with a mean age of 13.76 years $(\mathrm{SD}=2.20$; range $8-18)$. The non-referred sample consisted of 73 overweight children and adolescents (45 girls; 28 boys) with a mean age of 13.74 years (SD = 2.54; range 8-18). Both groups did not differ from each other in terms of age, $F(1,186)=0.00, P=0.96$, or gender distribution, $\chi^{2}(1)=0.05, P=0.82$.

\section{Measures}

Weight and height were measured. The adjusted BMI (AdjBMI) [(actual BMI/ Percentile 50 of BMI for age and gender $\times 100$ ] was calculated, based on normative data from the Netherlands [18] To standardize BMI across international samples, BMI z-scores were calculated based on normative data from the United States [Centers for Disease Control and Prevention 2000 standards: 32 ].

Socio-economic status (SES) was calculated using the Hollingshead Index of Social Position [23], based on parental education and occupation.

The Structured Clinical Interview for DSM-IV Childhood version [KID-SCID: 12, 22] is an interviewer-based semi-structured instrument to generate childhood DSM-IV diagnoses for clinical research studies, which is based on the SCID for adults [39]. Several studies provide support for the reliability and the validity of the KID-SCID [28, 29, 37]. To assure interrater reliability of diagnoses, we conducted a pilot study on the KID-SCID in 36 youngsters. Interviews were taped and scored by the interviewer and two independent raters (108 ratings). Cohen's $\kappa$ ranged from .79 and 1, suggesting excellent agreement.

The Eating Disorder Examination-Child version [ChEDE: 8] is a standard investigator-based interview measuring the severity of the core psychopathology of eating disorders and generating eating disorder diagnoses. The ChEDE contains four subscales designed to provide a profile of individuals in terms of four major areas of eating disorder symptoms: restraint, eating concern, shape concern and weight concern. In addition, the ChEDE assesses presence and frequency of different forms of overeating and compensatory behaviour. Several studies have demonstrated the reliability and validity of the ChEDE [10, $20,40,47]$. In the present study, Oxford criteria [15] were used to generate eating disorder diagnoses. Binge eating was defined as 'the presence of at least one objective bulimic episode over the past three 
months', irrespective of whether or not an eating disorder was present.

The Children's Depression Inventory [CDI: 26] assesses cognitive, affective and behavioural symptoms of depression in youth. The Dutch version of the CDI is considered a reliable and valid instrument [41, 42].

The Spence Children's Anxiety Scale [SCAS: 38] is a self-report questionnaire measuring specific symptoms of six DSM-IV anxiety disorders, namely generalised anxiety disorder, separation anxiety disorder, social phobia, panic disorder and agoraphobia, obsessive-compulsive disorder and physical injury fears. In psychometric studies on the Dutch version in large samples of school children, the SCAS has shown to be reliable and valid [30].

The Child Behavior Checklist [CBCL: 1] and the Youth Self Report [YSR: 2] are parallel questionnaires assessing several emotional and behavioural problem areas as reported respectively by the parent and the child. For both informants, a global internalizing and externalizing problem score can be obtained. Dutch versions of both the CBCL and the YSR are reliable and valid instruments for the assessment of psychological symptoms in youth $[44,45]$. Based on data from a large community sample of Dutch children and adolescents, $\mathrm{T}$-scores can be computed.

\section{Procedure}

The institutional review board of Ghent University approved the study protocol and informed consent was obtained from both children and parents. Interviews and questionnaires were administered by trained psychology students and psychologists. Questionnaires and interviews were held randomized on different days. Youngsters between 8 and 18 years of age who were diagnosed as being primary overweight (adjBMI $\geq 120$ ) were included. Exclusion criteria were mental retardation and the presence of developmental syndromes like Prader-Willi and Pervasive Developmental Disorder. In Belgium, children who are mentally retarded attend a specific type of education for children with special needs (so-called 'type 1' or 'type 2' education). Mental retardation was assessed by screening youngsters for educational level prior to the study.

To compose the referred group, youngsters were recruited via an obesity treatment centre. A detailed description of the treatment programme is given elsewhere [6]. Data were gathered in consecutive waves during a two year study period: each time in January and July, all eligible youngsters who had recently started the treatment, were invited to participate. Across the four waves, 123 obese children and adolescents met the inclusion criteria. The staff of the treatment centre requested to leave out one girl, one youngster refused to participate and six dropped out.

To compose the non-referred group, the study was firstly announced via advertisements in healthcare magazines, yielding a sample of 36 overweight youngsters. Secondly, participants were recruited via large-scale school mailings, resulting in an additional sample of 41 non-referred overweight adolescents. Each time, the study was described as research into the psychosocial well-being of youngsters "with a bigger size'. Youngsters meeting the general inclusion criteria were eligible when at the moment of the study they did not receive 'any treatment in order to lose weight with at least the help of a dietician'. Other forms of psychiatric or psychological help, defined as 'any treatment by a psychologist or a psychiatrist', were questioned. (Past) use of psychotropic medication was not inquired, so no data on this matter were available. Of those willing to participate, $5.19 \%$ $(n=4)$ received current overweight treatment and were therefore included in the referred sample. Two $(2.60 \%)$ youngsters received current psychological or psychiatric help. All participants in the non-referred group were aware that they would not receive any kind of treatment as part of the study. Due to the recruitment method, the non-referred group does parallel a population of overweight youngsters who are currently not under treatment for overweight but is not necessarily representative for the general population of overweight children and adolescents.

\section{Data analysis}

For the first research question, prevalence rates were expressed as a percentage for both samples. Rates between study groups were compared using ChiSquare statistics if all expected frequencies in the contingency table were $\geq 5$, otherwise a Likelihood Ratio test was performed. Comparisons were made for the overall prevalence of disruptive behaviour, mood, anxiety and eating disorders, for the prevalence of binge eating and for the prevalence of youngsters suffering from at least one mental disorder. Secondly, in case of significant differences in prevalence rates, odds ratios (OR) and 95\% confidence intervals (CI) were calculated using logistic regression analyses, controlling for possible differences in degree of overweight or/and SES between the referred and the non-referred group. For the third research question, a binary hierarchic logistic regression analysis was conducted with the presence of at least one diagnosis as the dependent variable. Age, gender $(0=$ boy; $1=$ girl), SES and degree of overweight were entered in block 1 , group $(0=$ non-referred; $1=$ referred $)$ was entered in block 2 and finally the interactions of (1) 
age and group, (2) gender and group, (3) SES and group and (4) adjBMI and group were entered in block 3. Finally, for the fourth research question, an Analysis of (Co)variance and four Multivariate Analyses of (Co)variance were conducted, each time with referral status as a factor and respectively the CDI total score, the SCAS subscales, the EDE subscales, the YSR subscales and the CBCL subscales as the dependent variables (possible differences in degree of overweight and SES between referred and non-referred youngsters were entered as covariates). All analyses were conducted using SPSS 15.0. P-values $\leq 0.05$ were considered statistically significant and all tests were two-tailed. In three youngsters, the (complete) administration of the KID-SCID was too much of a burden and had to be interrupted. Each time in one participant the administration of the KIDSCID or the EDE failed due to organisational reasons. It was decided to keep these youngsters in the other analyses.

\section{Results}

\section{Descriptives}

In the referred sample, the mean BMI was 33.99 $(\mathrm{SD}=5.60$; range 23.06-50.70), the mean adjusted BMI was 181.62 ( $\mathrm{SD}=25.92$; range $135.87-256.04)$ and the mean BMI $\mathrm{z}$-score was $2.27(\mathrm{SD}=0.29$; range 1.53-2.99). In the non-referred sample, the mean BMI was $27.35(\mathrm{SD}=4.32$; range 20.04-42.97), the mean adjusted BMI was 145.82 ( $S D=16.62$, range $120.53-$ 202.68) and the mean BMI z-score was 1.69 ( $\mathrm{SD}=$ 0.34 ; range $0.89-2.37$ ). The referred obese youngsters displayed a significantly higher adjusted BMI than the non-referred participants, $F(1,186)=110.35, \quad P<$ 0.001 . The referred group demonstrated significantly lower SES than the non-referred group, $F(1,183)=$ $10.98, P=0.001$.

\section{Prevalence of psychiatric disorders and confounding effects of degree of overweight and SES}

Forty-two referred (37.50\%) and 17 non-referred $(23.29 \%)$ youngsters received one or more psychiatric diagnoses. In the referred group, $9(8.04 \%)$ youngsters were diagnosed with at least one disruptive behaviour disorder, $9(8.04 \%)$ with at least one mood disorder, $18(16.22 \%)$ with at least one anxiety disorder and $13(11.40 \%)$ with at least one eating disorder. In the non-referred group, five participants $(6.85 \%)$ were diagnosed with at least one behavioural disorder, five $(6.85 \%)$ with at least one mood disorder, $10(13.70 \%)$ with at least one anxiety disorder and one (1.37\%) with an eating disorder. In the referred group, there were 33 subjects $(29.46 \%)$ with one diagnosis, six with two diagnoses $(5.36 \%)$, two with three diagnoses $(1.79 \%)$ and one with four diagnoses $(0.89 \%)$. In the non-referred group, there were 11 subjects $(15.07 \%)$ with one diagnosis, five with two diagnoses $(6.85 \%)$ and one with four diagnoses $(1.37 \%)$. Binge eating was found in $31.58 \%$ of the referred versus in $12.33 \%$ of the non-referred youngsters. An overview of the prevalence rates is depicted in Table 1.

The referred and the non-referred group differed significantly on the number of participants receiving at least one diagnosis, $\chi^{2}(1)=4.11, P<0.05$, on the prevalence of 'full blown' eating disorders, $L R(1)=$ 8.03, $P<0.01$, and on the prevalence of binge eating, $\chi^{2}(1)=9.03, P<0.01$. After controlling for differences in degree of overweight and SES between the referred and the non-referred group, none of the calculated odds ratios appeared significantly increased.

\section{The moderating role of demographic variables and degree of overweight in the association of referral status and mental disorders in overweight youngsters}

In block 1 age predicted mental disorder significantly, Wald $(1)=4.11, P<0.05$. Youngsters with at least one diagnosis, were significantly older than youngsters without, $F(1.183)=5.67, P<0.05$. In block 3 the interaction of SES and referral status appeared a significant predictor, $\operatorname{Wald}(1)=6.36, P=0.01$. Although in the referred group youngsters with at least one diagnosis were somewhat lower in SES than youngsters without, no significant differences emerged, $F(1.107)=2.42, P=0.12$. However, in the non-referred group youngsters with at least one mental disorder exhibited significantly higher SES than youngsters without, $F(1.71)=5.39, P<0.05$.

\section{Self- and parent reported symptom severity and confounding effects of degree of overweight and SES}

Table 2 displays means/standard deviations on the questionnaires administered and on the EDE subscales, and $F$-values/significance levels before taking into account between group differences in degree of overweight and SES. As can be seen, referred youngsters displayed significantly more self-reported depressive, $F(1.164)=3.84, P=0.05$, and parent-reported internalizing symptoms, $F(1.166)=7.97$, $P<0.01$. When degree of overweight and SES were included as covariates in the analyses, no differences between the referred and the non-referred group were 
Table 1 Prevalence of DSM-IV disorders in referred and non-referred obese children and adolescents

\begin{tabular}{|c|c|c|c|c|c|c|}
\hline & \multicolumn{2}{|c|}{ Referred } & \multicolumn{2}{|c|}{ Non-referred } & \multirow[t]{2}{*}{$X^{2}(1)$} & \multirow[t]{2}{*}{ OR $(95 \% \text { Cl })^{\mathrm{a}}$} \\
\hline & $N$ & $\%$ & $N$ & $\%$ & & \\
\hline Attention deficit hyperactivity disorder & 1 & 0.89 & 2 & 2.74 & & \\
\hline Oppositional defiant disorder & 4 & 3.57 & 2 & 2.74 & & \\
\hline Conduct disorder & 3 & 2.68 & 1 & 1.37 & & \\
\hline Conduct disorder-NOS & 1 & 0.89 & 0 & 0.00 & & \\
\hline Any disruptive behaviour disorder & 9 & 8.04 & 5 & 6.85 & 0.09 & \\
\hline Major depressive disorder & 5 & 4.46 & 3 & 4.11 & & \\
\hline Manic episode & 0 & 0.00 & 0 & 0.00 & & \\
\hline Hypomanic episode & 1 & 0.90 & 1 & 1.37 & & \\
\hline Dysthymic disorder & 1 & 0.90 & 0 & 0.00 & & \\
\hline Major depressive disorder-NOS & 2 & 1.80 & 1 & 1.37 & & \\
\hline Any mood disorder & 9 & 8.04 & 5 & 6.85 & 0.09 & \\
\hline Separation anxiety disorder & 2 & 1.80 & 1 & 1.37 & & \\
\hline Social phobia & 0 & 0.90 & 2 & 2.74 & & \\
\hline Specific phobia & 7 & 6.31 & 5 & 6.85 & & \\
\hline Obsessive compulsive disorder & 1 & 0.90 & 1 & 1.37 & & \\
\hline Post traumatic stress disorder & 4 & 3.60 & 2 & 2.74 & & \\
\hline Generalised anxiety disorder & 0 & 0.00 & 1 & 1.37 & & \\
\hline Panic disorder & 0 & 0.00 & 0 & 0.00 & & \\
\hline Agoraphobia & 0 & 0.00 & 0 & 0.00 & & \\
\hline Anxiety disorder-NOS & 7 & 6.31 & 2 & 1.37 & & \\
\hline Any anxiety disorder & 18 & 16.22 & 10 & 13.70 & 0.22 & \\
\hline Adjustment disorder & 4 & 3.60 & 0 & 0.00 & & \\
\hline Binge eating disorder & 10 & 8.77 & 1 & 1.37 & & \\
\hline Bulimia nervosa & 3 & 2.63 & 0 & 0.00 & & \\
\hline Any eating disorder & 13 & 11.40 & 1 & 1.37 & $8.03^{b, * *}$ & $6.30(0.68-58.81)$ \\
\hline Binge eating & 36 & 31.58 & 9 & 12.33 & $9.03^{* *}$ & $1.88(0.71-4.98)$ \\
\hline Any disorder & 42 & 37.50 & 17 & 23.29 & $4.11^{*}$ & $1.66(0.72-3.84)$ \\
\hline
\end{tabular}

NOS not otherwise specified

${ }^{*} P<0.05 ;{ }^{* *} P<0.01$

${ }^{a}$ Adjusted odds ratios (OR) and $95 \%$ confidence intervals $(\mathrm{Cl})$ were calculated using logistic regression analyses, controlling for degree of overweight and socio-economic status, with the non-referred group as reference

${ }^{\mathrm{b}} \mathrm{A}$ Likelihood Ratio Test was performed

\begin{tabular}{|c|c|c|c|c|}
\hline & $\alpha$ & $\begin{array}{l}\text { Referred } \\
M(S D)\end{array}$ & $\begin{array}{l}\text { Non-referred } \\
M(\mathrm{SD})\end{array}$ & $F^{\mathrm{a}}$ \\
\hline Children's Depression Inventory & 0.86 & $12.70(7.17)$ & $10.63(6.15)$ & $3.84^{*}$ \\
\hline Spence Children's Anxiety Scale & & & & 1.89 \\
\hline Separation anxiety disorder & 0.71 & $3.94(3.09)$ & $3.19(2.86)$ & \\
\hline Social anxiety disorder & 0.69 & $5.03(3.22)$ & $5.53(3.22)$ & \\
\hline Obsessive compulsive disorder & 0.77 & $3.28(3.08)$ & $3.67(3.31)$ & \\
\hline Panic disorder/Agoraphobia & 0.78 & $3.58(3.50)$ & $3.86(4.01)$ & \\
\hline Fear of physical injury & 0.47 & $3.24(2.54)$ & $3.87(2.60)$ & \\
\hline Generalized anxiety disorder & 0.72 & $5.22(2.91)$ & $5.53(3.46)$ & \\
\hline Total anxiety score & 0.91 & $24.29(14.24)$ & $25.66(15.07)$ & \\
\hline Eating Disorder Examination & & & & 1.62 \\
\hline Restraint & 0.60 & $5.63(5.46)$ & $6.34(5.34)$ & \\
\hline Eating concern & 0.57 & 3.09 (3.59) & $2.29(3.57)$ & \\
\hline Weight concern & 0.64 & $10.14(5.22)$ & $9.16(5.44)$ & \\
\hline Shape concern & 0.81 & $16.42(8.92)$ & $13.96(10.68)$ & \\
\hline Youth Self Report & & & & 1.82 \\
\hline Internalizing problems & 0.87 & $61.27(10.82)$ & 57.62 (11.74) & \\
\hline Externalizing problems & 0.83 & $56.07(10.43)$ & $54.00(8.82)$ & \\
\hline Child Behavior Checklist & & & & $4.86^{* *}$ \\
\hline Internalizing problems & 0.90 & $63.62(11.58)$ & $58.82(9.86)$ & $7.97^{* *}$ \\
\hline Externalizing problems & 0.92 & $58.96(12.61)$ & $58.15(12.47)$ & 0.17 \\
\hline
\end{tabular}

${ }^{*} P<0.05 ;{ }^{* *} P<0.01$

a Displayed $F$-values and significance levels do not take into account differences in degree of overweight and socioeconomic status between referred and non-referred overweight youngsters
Table 2 Means, standard deviations en Cronbach's alphas for the referred and the non-referred obese youngsters on all questionnaires administered and the EDE subscales 
found. However, a trend towards a higher level of parent reported symptomatology remained, $F(2.160)=$ 2.92, $P=0.06$. More specifically, referred youngsters still displayed significantly higher scores on the CBCL internalizing problems subscale, $F(1.161)=4.62$, $P<0.05$.

\section{Discussion}

The present study revealed that a substantial proportion of overweight youngsters suffer from mental disorders. Overall, a higher level of psychopathology was found in the referred group. More specifically, referred youngsters displayed more eating disorders and binge eating than non-referred youngsters and exhibited a greater severity of self- and parent-reported internalizing symptoms. Referral was also associated with a higher degree of overweight and lower SES. After controlling statistically for these preexisting differences in degree of overweight and SES, only the greater severity of parent-reported internalizing symptoms in referred youth remained significant. Older age appeared generally predictive for the presence of mental disorders and in the non-referred group SES was positively associated with psychiatric disorder. Overall, in line with earlier research, these findings suggest heterogeneity among overweight individuals.

In this study, clinical interviews, known as the 'gold standard' for assessment of psychiatric disorders, were used. A relatively large sample was recruited, including boys as well as girls and children as well as adolescents, and special attention was given to state-of-the-art assessment of eating disorders. Moreover, we controlled statistically for pre-existing differences in degree of overweight and demographic factors between the referred and the non-referred sample. With the present methodologically sound design, an attempt was made to deal with the flaws of earlier studies. Finally, this is the first time that demographic factors were examined as potential moderators in the association of referral status and mental disorder.

Differences between referred and non-referred overweight youngsters were not as pronounced as expected. Surprisingly, this was even the case when possible confounding effects of degree of overweight and SES were not taken into account. In the early nineties, it was hypothesized that especially the concurrence of obesity and comorbid psychopathology lead to referral. Due to the stigma associated with psychiatry, overweight individuals were presumed to prefer obesity treatment instead of psychotherapy, leading to substantially higher degrees of psychopa- thology in referred groups [27]. Apparently, this socalled 'stigma hypothesis' seems to hold no longer. Comparison of the present findings with the study by Braet et al. [5] indicates that for the referred group CBCL-scores in this study were somewhat higher, whereas for the non-referred group, the increase was substantial. During the past decade, the issue of overweight has received a tremendous amount of attention. Prevention programmes have been set up that focus on attaining a healthy life style. Hence, overweight individuals are permanently in the picture' and implicitly blamed for not being able to take responsibility for their health. Briefly, whereas the social discrimination associated with obesity [34] seems of all times, nowadays being overweight in itself has become a major stressor. Concerning referral, this 'spirit of the times hypothesis' has at least one important implication: overweight in itself might be a sufficient reason for people to seek help. Consequently, referred youngsters will display more heterogeneity and differences between referred and nonreferred groups will become less marked.

The precise nature of the association between obesity and psychopathology remains unclear. In the present study, it was demonstrated that when overweight children become older, they are more likely to develop a mental disorder. In line with findings by Mustillo et al. [31], we put forward the idea that being overweight in early life might form a scar, leading to psychopathology in individuals confronted with stress. In line with this so-called diathesis-stress perspective on psychopathology [35], the 'spirit of the times hypothesis' predicts a general increase of psychological problems in overweight individuals, as both a breeding ground for diatheses and higher stress levels are created.

Prevalence rates of psychiatric disorders in the present referred sample were lower than those in the studies by Britz et al. [7] and Vila et al. [46]. However, the former study also demonstrated substantially higher prevalence figures as compared with the latter. This might partly be due to the differences in age group and to the assessment of lifetime diagnoses by Britz et al. [7] but not by Vila et al. [46]. Moreover, it is also important to distinguish between so called investigator-based interviews (K-SADS-R, KID-SCID, ChEDE) on the one hand and respondent-based interviews (M-CIDI) on the other hand. Respondentbased interviews (often computerised) are highly cost-effective and predominantly used in epidemiological research. However, it could be assumed that interviewer-based formats yield higher quality data [25] which seriously hampers comparison of studies that differ on the interview method used. Hence, methodologically the present study most closely resembles the one by Vila et al. [46] and leads to 
similar conclusions: a substantial number of referred obese youngsters suffer from mental disorders, mostly anxiety disorders. Prevalence rates in the present study were more or less similar for affective disorders ( $8 \%$ vs. $12 \%)$ but lower for disruptive behaviour ( $8 \%$ vs. $16 \%)$ and anxiety disorders $(16 \%$ vs. $32 \%)$. One reason might be that in the Vila et al. study, the K-SADS-R was administered to both the children and their parents: application of the so called 'OR'- rule might have erroneously enhanced the number of diagnoses. Comparison of results in the non-referred group with the community studies by Lamertz and colleagues [27] is difficult due to the use of a respondent-based interview assessing life-time diagnoses. Mustillo et al. [31] used an interviewerbased format but the authors only presented prevalence rates summed over the 7-year study period, which is more or less a measure of lifetime diagnoses.

Remarkably, the prevalence of ADHD in the present study was lower than the worldwide general population prevalence rate of about 5\% [33]. This is the more surprising in light of mounting evidence for a significant comorbidity between obesity and ADHD $[4,24]$. We assume that especially for ADHD, relying on the information of a child or an adolescent leads to an underestimation of the prevalence. Practice parameters for the assessment of youngsters with ADHD consider the parent interview as the core of the assessment process and standardized interviews of children and adolescents as less useful [13]. First of all, some children and most adolescents with ADHD are able to maintain attention and behavioural control in the office setting, which might influence the investigator's judgements. Secondly, youngsters might have difficulty in recalling whether ADHDsymptoms occurred before the age of 7 years and/or in recognizing their ADHD-symptoms as 'problematic', as required by DSM to meet criteria for the diagnosis. It should however be noted that this study did not aim to provide prevalence estimates of DSMdisorders in overweight youth. The main objective was to investigate differences between referred and non-referred youngsters. As both the interview and the interviewers were kept constant across samples, we consider the methodology adequate for the purpose of the present study.

In the referred group, 32\% reported binge eating episodes. The prevalence of binge eating was clearly in line with the latest findings by Glasofer and colleagues [20]. Although the presence of severe eating pathology was largely constricted to referred youngsters, it should be noted that even in the non-referred sample $12 \%$ reported binge eating episodes and that eating, weight and shape concern were present to the same degree as in the referred group. Comparison of our findings with the methodologically parallel study of Decaluwé and Braet [11] also seems to indicate that in referred obese youngsters the prevalence of binge eating has augmented during the past years. In sum, from childhood and adolescence onwards, overweight and eating disorders become (more and more) intertwined. As we know that overweight in youth is a risk factor for the development of eating disorders in adulthood it could be assumed that eating pathology in overweight is likely to persist and aggravate in later life. Longitudinal research is now needed to investigate this.

A major limitation of the study is that the nonreferred sample was not recruited in a truly population-based fashion. Due to the use of advertisements and school mailings, the present non-referred sample is not necessarily representative for the general population of overweight children and adolescents. Both in the study by Braet et al. [5] and the study by Erermis et al. [14], non-referred overweight youngsters were also recruited via schools, more precisely by selecting overweight youngsters on the basis of the school physician's data on weight and height. In such designs, youngsters and their parents opt to participate, which limits the external validity of the study. The study by Britz and colleagues [7] was unique by looking at real population based obese adolescents. However, even when these authors selected the nonreferred adolescents with the highest BMI, referred youngsters were still substantially heavier. Also in the present study, referral was associated with a higher degree of overweight. We assume that a ceiling effect might be at play: once a certain degree of overweight is attained, there is a very high probability for people to seek help. As such, it is very difficult to match referred youth with population based extremely obese adolescents: thousands of youngsters need to be screened and consequently researchers are forced to administer less reliable respondent-based interviews. Moreover, a study including a truly population-based sample will probably suffer from inadequate power to form conclusions, since one presumes prevalence rates of mental disorders to be considerably lower in community samples. Due to low prevalence rates, wider CI's are obtained, generally leading to statistically insignificant results.

In the non-referred group youngsters with high SES appeared more vulnerable for mental disorders. It could be argued that, due to our recruitment method, subjects of higher SES with a psychiatric diagnosis were more likely to participate. However, research in adults can also throw light upon this unexpected finding. In a community sample of adults, Simon et al. [36] recently demonstrated a stronger association of obesity and mental disorders in individuals with higher educational attainment. This high SES group was also among those with the lowest overall rates of 
obesity. Simon and colleagues [36] hypothesize that the social discrimination of overweight individuals has a stronger impact in socio-demographic groups with lower obesity rates. In line with our 'spirit of the times hypothesis', we also assume that the mere presence of obesity might be most stressful in high SES groups. It should be taken into account that mechanisms of referral are also a function of the country's health care insurance system. Although in Europe almost universal coverage of the population is provided for the majority of health care services, there are large differences between countries in the specific public/private insurance mix. For Belgium, analyses even indicate inequity favoring the poor [43], which might help to explain why in the referred group youngsters displayed lower SES. We hypothesize that the stigma associated with help seeking prevents the high SES group from looking for treatment. In countries with private insurance, (specialized) health care is more likely to be a status symbol.

Further research will need to identify crucial factors that prevent individuals from seeking help. Moreover, longitudinal studies are needed to understand how obesity and psychopathology are related. In this regard, the diathesis-stress perspective seems promising. Next, one could wonder how obesity treatment in overweight youngsters with comorbid psychopathology must be outlined. Research should focus on the extent to which psychopathology in referred youth is associated with drop-out, weight loss and relapse. It needs to be investigated how many youngsters still suffer from mental disorders after standardized obesity treatment and whether additional psychotherapy (and what kind of psychotherapy) during obesity treatment is helpful. Finally, it seems interesting to explore how referral history hampers adherence to overweight treatment.

To conclude, the results of the present study demonstrate that also in non-referred groups, a substantial proportion of youngsters suffer from comorbid psychopathology. Hence, from a mental health perspective, it could be argued that interventions should not solely target referred youth. Adequate care for youngsters presenting for treatment of overweight requires clinicians to be alert on and address possible psychopathology in general and eating pathology in particular. This pleads for a multidisciplinary approach, including close collaboration with liaison psychiatrists and psychologists.

\section{References}

1. Achenbach TM (1991) Manual for the child behavior checklist 4-18 and 1991 profile. University of Vermont Department of Psychiatry, Burlington

2. Achenbach TM (1991) Manual for the youth self report and 1991 profile.

University of Vermont, Department of Psychiatry, Burlington

3. Achenbach TM, Mcconaughy SH, Howell CT (1987) Child adolescent behavioral and emotional-problemsimplications of cross-informant correlations for situational specificity. Psychol Bull 101:213-232

4. Agranat-Meged AN, Deitcher C, Goldzweig G, Leibenson L, Stein M, GaliliWeisstub E (2005) Childhood obesity and attention deficit/hyperactivity disorder: a newly described comorbidity in obese hospitalized children. Int J Eat Disord 37:357-359

5. Braet C, Mervielde I, Vandereycken W (1997) Psychological aspects of childhood obesity: a controlled study in a clinical and nonclinical sample. J Pediatr Psychol 22:59-71

6. Braet C, Tanghe A, Decaluwe V, Moens E, Rosseel Y (2004) Inpatient treatment for children with obesity: weight loss, psychological well-being, and eating behavior. J Pediatr Psychol 29:519-529
7. Britz B, Siegfried W, Ziegler A, Lamertz C, Herpertz-Dahlmann BM, Remschmidt $\mathrm{H}$, Wittchen $\mathrm{HU}$, Hebebrand J (2000) Rates of psychiatric disorders in a clinical study group of adolescents with extreme obesity and in obese adolescents ascertained via a population based study. Int J Obes 24:17071714

8. Bryant-Waugh RJ, Cooper PJ, Taylor CL, Lask BD (1996) The use of the eating disorder examination with children: a pilot study. Int J Eat Disord 19:391-397

9. Costello EJ, Egger H, Angold A (2005) 10-year research update review: the epidemiology of child and adolescent psychiatric disorders: I. Methods and public health burden. J Am Acad Child Adolesc Psychiatry 44:972-986

10. Decaluwe V, Braet C (2004) Assessment of eating disorder psychopathology in obese children and adolescents: interview versus self-report questionnaire. Behav Res Ther 42:799-811

11. Decaluwe V, Braet C (2003) Prevalence of binge-eating disorder in obese children and adolescents seeking weightloss treatment. Int J Obes 27:404-409
12. Dreessen L, Stroux A, Weckx M (1998) Nederlandse vertaling van het gestructureerd klinisch interview voor DSM-IV-kind versie (KID-SCID; Versie 1.0). [Dutch translation of the structured clinical interview for DSMIV—child edition]. Maastricht University, Maastricht

13. Dulcan M, Dunne JE, Ayres W, Arnold V, Benson RS, Bernet W, Bukstein O, Kinlan J, Leonard H, Licamele W, McClellan J, Sloan LE, Miles CM (1997) Practice parameters for the assessment and treatment of children, adolescents, and adults with attention-deficit/ hyperactivity disorder. J Am Acad Child Adolesc Psychiatry 36:S85-S121

14. Erermis S, Cetin N, Tamar M, Bukusoglu N, Akdeniz F, Goksen D (2004) Is obesity a risk factor for psychopathology among adolescents? Pediatr Int 46:296-301

15. Fairburn CG, Cooper Z (1993) The eating disorder examination (12th edn). In: Fairburn CG, Wilson T (eds) Binge eating: nature, assessment and treatment. Guilford Press, New York, 317-331

16. Fairburn CG, Harrison PJ (2003) Eating disorders. Lancet 361:407-416 
17. Faith MS, Matz PE, Jorge MA (2002) Obesity-depression associations in the population. J Psychosom Res 53:935-942

18. Fredriks AM, van Buuren S, Wit JM, Verloove-Vanhorick SP (2000) Body index measurements in 1996-7 compared with 1980. Arch Dis Child 82:107-112

19. Friedman MA, Brownell KD (1995) Psychological correlates of obesity-moving to the next research generation. Psychol Bull 117:3-20

20. Glasofer DR, Tanofsky-Kraff M, Eddy KT, Yanovski SZ, Theim KR, Mirch MC, Ghorbani S, Ranzenhofer LM, Haaga D, Yanovski JA (2007) Binge eating in overweight treatment-seeking adolescents. J Pediatr Psychol 32:95105

21. Herpertz S, Burgmer R, Stang A, de Zwaan M, Wolf AM, Chen-Stute A, Hulisz T, Jockel KH, Senf W (2006) Prevalence of mental disorders in normal-weight and obese individuals with and without weight loss treatment in a German urban population. J Psychosom Res 61:95-103

22. Hien D, Matzner FJ, First MB, Spitzer RL, Gibbon M, Williams JBW (1994) Structured clinical interview for DSMIV-child edition (version 1.0). Columbia University, New York

23. Hollingshead A (1975) Four factor index of social status. Yale University Press, New Haven

24. Holtkamp K, Konrad K, Muller B, Heussen N, Herpertz S, HerpertzDahlmann B, Hebebrand J (2004) Overweight and obesity in children with attention-deficit/hyperactivity disorder. Int J Obes 28:685-689

25. Klein DN, Dougherty LR, Olino TM (2005) Toward guidelines for evidencebased assessment of depression in children and adolescents. J Clin Child Adolesc Psychol 34:412-432

26. Kovacs M (1996) Presentation and course of major depressive disorder during childhood and later years of the life span. J Am Acad Child Adolesc Psychiatry 35:705-715

27. Lamertz CM, Jacobi C, Yassouridis A, Arnold K, Henkel AW (2002) Are obese adolescents and young adults at higher risk for mental disorders? A community survey. Obes Res 10:1152-1160
28. Matzner F (1994) Videotapes as training tools for the development of the KID-SCID. In: American Academy of child and adolescent psychiatry 42nd annual meeting. American Academy of child and adolescent psychiatry, Washington, DC

29. Matzner F, Silva RR, Silvan M, Chowdhury M, Nastasi L (1997) Preliminary test-retest reliability of the KID-SCID. In: American Psychiatric Association annual meeting. American Psychiatric Association, San Diego

30. Muris P, Schmidt H, Merckelbach $\mathrm{H}$ (2000) Correlations among two selfreport questionnaires for measuring DSM-defined anxiety disorder symptoms in children: the screen for child anxiety related emotional disorders and the Spence children's anxiety scale. Pers Individ Dif 28:333-346

31. Mustillo S, Worthman C, Erkanli A, Keeler G, Angold A, Costello EJ (2003) Obesity and psychiatric disorder: developmental trajectories. Pediatrics 111:851-859

32. Ogden CL, Kuczmarski RJ, Flegal KM, Mei Z, Guo S, Wei R, Grummer-Strawn LM, Curtin LR, Roche AF, Johnson CL (2002) Centers for disease control and prevention 2000 growth charts for the United States: improvements to the 1977 National Center for Health statistics version. Pediatrics 109:45-60

33. Polanczyk G, de Lima MS, Horta BL, Biederman J, Rohde LA (2007) The worldwide prevalence of ADHD: a systematic review and metaregression analysis. Am J Psychiatry 164:942-948

34. Puhl RM, Brownell KD (2001) Bias, discrimination, and obesity. Obes Res 9:788-805

35. Rutter M (2006) Genes and behavior: nature-nurture interplay. Blackwell Publishing, Oxford

36. Simon GE, Von Korff M, Saunders K, Miglioretti DL, Crane PK, van Belle G, Kessler RC (2006) Association between obesity and psychiatric disorders in the US adult population. Arch Gen Psychiatry 63:824-830

37. Smith DC, Huber DL, Hall JA (2005) Psychometric evaluation of the structured clinical interview for DSM-IV childhood diagnoses (KID-SCID). J Hum Behav Soc Environ 11:23-40
38. Spence SH (1998) A measure of anxiety symptoms among children. Behav Res Ther 36:545-566

39. Spitzer RL, Williams JBW, Gibbon M (1986) Structured clinical interview for DSM-III-R. New York State Psychiatric Institute, Biometrics Research, New York

40. Tanofsky-Kraff M, Yanovski SZ, Wilfley DE, Marmarosh C, Morgan CM, Yanovski JA (2004) Eating-disordered behaviors, body fat, and psychopathology in overweight and normalweight children. J Consult Clin Psychol 72:53-61

41. Timbremont B, Braet C (2002) Children's depression inventory: Nederlandstalige versie [children's depression inventory: Dutch version]. Swets \& Zeitlinger, Lisse

42. Timbremont B, Braet C, Dreessen L (2004) Assessing depression in youth: relation between the children's depression inventory and a structured interview. J Clin Child Adolesc Psychol 33:149-157

43. van Doorslaer E, Masseria C, Koolman $X$ (2006) Inequalities in access to medical care by income in developed countries. Can Med Assoc J 174:177183

44. Verhulst FC, Van der Ende J, Koot HM (1996) Handleiding voor de CBCL/4-18 [manual for the child behavior checklist and revised child behavior profile]. Sophia Children's Hospital, Department of Child and Adolescent Psychiatry, Rotterdam

45. Verhulst FC, Van der Ende J, Koot HM (1997) Handleiding voor de youth selfreport [manual for the youth self report and profile]. Sophia Children's Hospital, Department of Child and Adolescent Psychiatry, Rotterdam

46. Vila G, Zipper E, Dabbas M, Bertrand C, Robert JJ, Ricour C, Mouren-Simeoni MC (2004) Mental disorders in obese children and adolescents. Psychosom Med 66:387-394

47. Watkins B, Frampton I, Lask B, BryantWaugh R (2005) Reliability and validity of the child version of the eating disorder examination: a preliminary investigation. Int J Eat Disord 38:183187 